\title{
Simulation and Optimization in Production Logistics Based on eM-Plant Platform
}

\author{
XinJian Zhou, XiangBin Xu, and Wei Zhu \\ School of Mechatronics Engineering, East China Jiaotong University, \\ 330013 Nanchang, P.R. China \\ champagnewq@yahoo.com.cn
}

\begin{abstract}
The optimization of production logistics system is an important way to improve enterprise's productivity, cut down cost and improve equipment's utilization. Production logistics system is highly randomized, complicated and discrete system, which can hardly be modeled and analyzed in the traditional way, so computer simulation technology and eM-Plant simulation platform were introduced in the paper to model and analyze production logistics system, more than modeling eM-Plant also can analyze production logistics system's equipment's utilization, working efficiency, production capacity statistics effectively, which can offer useful guideline for production logistics system optimization and scientific decision-making.
\end{abstract}

Keywords: Production logistics, eM-Plant, Simulation, Optimization.

\section{Introduction}

Production logistics should feature characteristics such as continuousness, smooth, parallel, proportionality, balance, flexibility, but many enterprises has production logistics problem including low productivity, more WIPs, long production cycle and waste of resources. The computer simulation technology is a effective way to find and solve these problems, the article takes eM-Plant simulation software to set up $\mathrm{X} 4105 \mathrm{BC}$ diesel engine's production logistics and optimize simulation models, the simulation and verification can offer great decision making support for the assembly line's production logistics optimization, which ensure the scientific management decisions.

\section{The Assembly Line's Production Logistics}

\subsection{Process Route}

The $\mathrm{X} 4105 \mathrm{BC}$ diesel engine is the main product of some manufacturing enterprises, the product mode of $\mathrm{X} 4105 \mathrm{BC}$ diesel engine is in a multi-variety, small batch and 
make-to-order way. The whole Diesel assembly process includes 22 procedures, which is listed in Table.1.

Table 1. X4105BC diesel engine assembly route

\begin{tabular}{llllll}
\hline No & Procedure & No & Procedure & No & Procedure \\
\hline 1 & Crankshaft & 8 & Flywheel & 15 & Rocker \\
2 & Cylinder & 9 & Oil Pan & 16 & Gears Lid \\
3 & Piston and Rod & 10 & Starter and Generator & 17 & $\begin{array}{l}\text { Nozzle and } \\
\text { Cylinder Cover }\end{array}$ \\
4 & Flywheel Cover & 11 & Cylinder Lid & 18 & Exhaust Pipe \\
5 & Oil pipe & 12 & Water Pump and Pipe & 19 & Water Manifold \\
6 & Oil Cooler & 13 & $\begin{array}{l}\text { High-Pressure Oil } \\
\text { Pump and Air Filter }\end{array}$ & 20 & Pulley Wheel \\
7 & Left Side Cover & 14 & $\begin{array}{l}\text { Gears and Intake } \\
\text { Manifold }\end{array}$ & 21 & Oil Filter \\
\hline
\end{tabular}

\subsection{Production Lline Layout}

$\mathrm{X} 4105 \mathrm{BC}$ diesel engine assembly line was built on a $108 \mathrm{~m}$-long non-power roller conveyor belt, the layout of the assembly line shown in Fig.1.

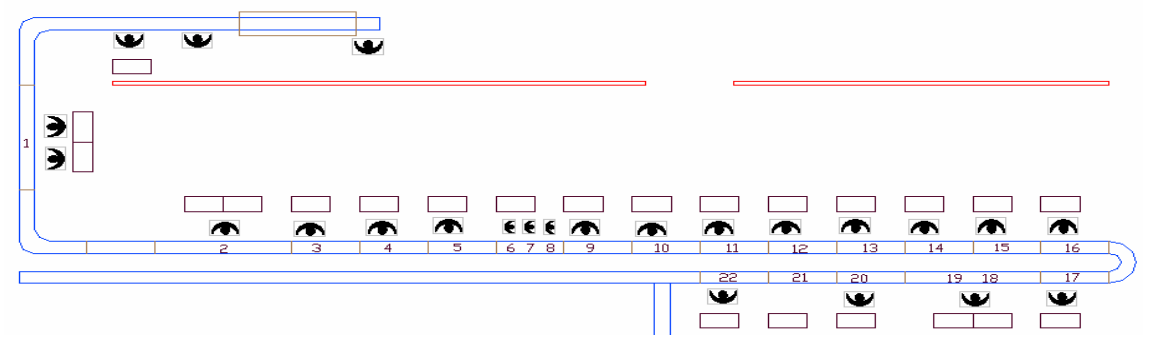

Fig. 1. The layout of the assembly line

\section{Production Logistics Simulation Model}

\subsection{Assembly Line Simulation Bbased on eM-Plant}

Based on the X4105BC diesel engine process route and assembly line layout, the simulation model of the Assembly Line X4105BC build in eM-Plant is showed in Fig.2. 


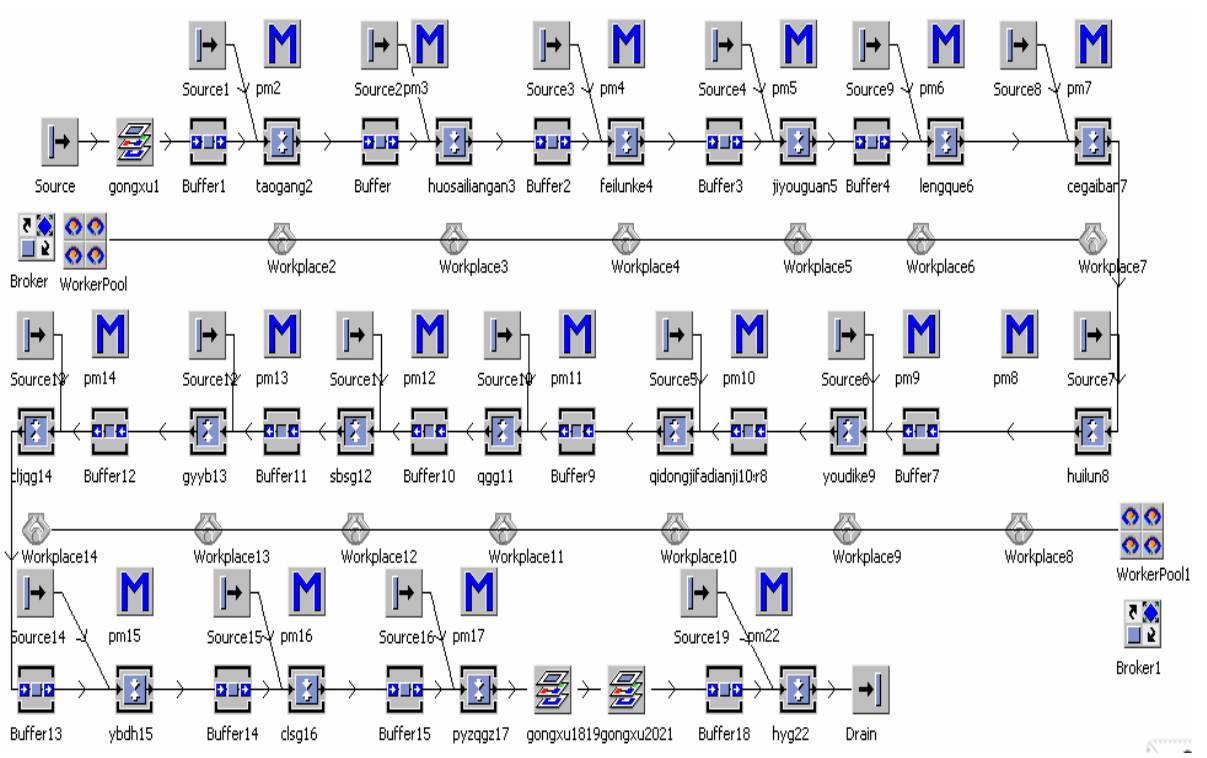

Fig. 2. The eM-plant simulation model of X4105BC assembly line

In the simulation model, the assembly buffers are modeled in EM-plant's Buffer component, the Capacity property of the EM-plant's Buffer can specify buffer maximal number parts which can accommodate; the workstations are modeled in EMplant's ParallelProc component, the set-up and processing time property of the EMplant's ParallelProc can specify the workstation's setting-up and processing time; EM-plant's WorkerPool component is used to model worker dispatching,EM-plant's Broker component can set worker dispatching rules, witch can route worker from the WorderPool to the right workstations.

\subsection{The Simulation Results by eM-Plant}

Once the assembly line's simulation model is completed, run the simulation model, eM-plant can offer many kinds of statistics table and chart for us to analyze and optimize. Here we take the workstation's working balance histogram to analyze the workstation working load, which is show in Fig.3.The blue heap in the workstation's working balance shows one worker's total working time, the red heap in the workstation's working balance mean balance lost of the assembly line. Fig 3. tells us than the there is huge balance loss in the assembly line, which results in waste of resources and time, and the assembly line must be optimized. 


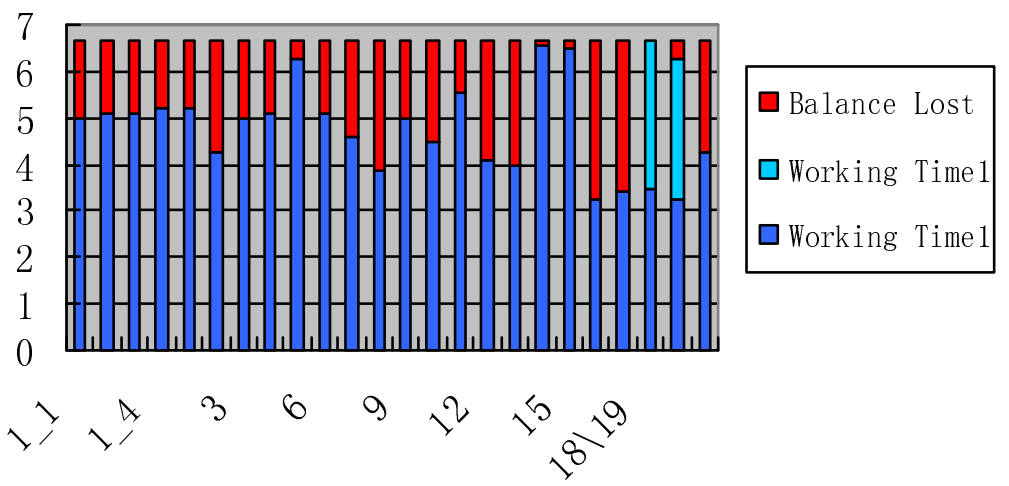

Fig. 3. Assembly Line Balance Histogram

\section{The Optimization and Simulation of Production Logistics}

\subsection{Assembly Line Process Route Optimization}

After field investigation based on the eM-plant simulation results, we decomposition working procedures 1 and divide it into 5 sub-working procedures, namely working procedures1,2,3,4,5. since working procedures 18,19 and 20,21 are completed by a workers, so we combine working procedures 18,19 and 20,21 into one. The assembly process route after adjustment is shown in Table 2 .

Table 2. X4105BC diesel dngine assembly route after optimization

\begin{tabular}{|c|c|c|c|c|c|}
\hline No & Procedure & No & Procedure & No & Procedure \\
\hline 1 & $\begin{array}{l}\text { Body Washed by } \\
\text { Machine }\end{array}$ & 9 & Oil pipe & 17 & $\begin{array}{l}\text { High-Pressure Oil } \\
\text { Pump and Air } \\
\text { Filter }\end{array}$ \\
\hline 2 & $\begin{array}{l}\text { Body Washed by } \\
\text { Hand }\end{array}$ & 10 & Cylinder Oil Cooler & 18 & $\begin{array}{l}\text { Gears and Intake } \\
\text { Manifold }\end{array}$ \\
\hline 3 & $\begin{array}{l}\text { Camshaft } \\
\text { Cushion }\end{array}$ & 11 & Left Side Cover & 19 & Rocker \\
\hline 4 & Camshaft Bush & 12 & Flywheel & 20 & $\begin{array}{l}\text { Gears Lid Exhaust } \\
\text { pipe }\end{array}$ \\
\hline 5 & Camshaft & 13 & Oil Pan & 21 & $\begin{array}{l}\text { Nozzle and } \\
\text { Cylinder Cover }\end{array}$ \\
\hline 6 & Cylinder & 14 & Starter and Generator & 22 & $\begin{array}{l}\text { Exhaust pipe and } \\
\text { Pulley Wheel }\end{array}$ \\
\hline 7 & Piston and Rod & 15 & Cylinder Lid & 23 & $\begin{array}{l}\text { Pulley Wheel and } \\
\text { Oil Filter }\end{array}$ \\
\hline 8 & Flywheel Cover & 16 & Water Pump and Pipe & 24 & Return Oil Pipe \\
\hline
\end{tabular}


And the assembly sequence after Optimized is shown in Fig.4.

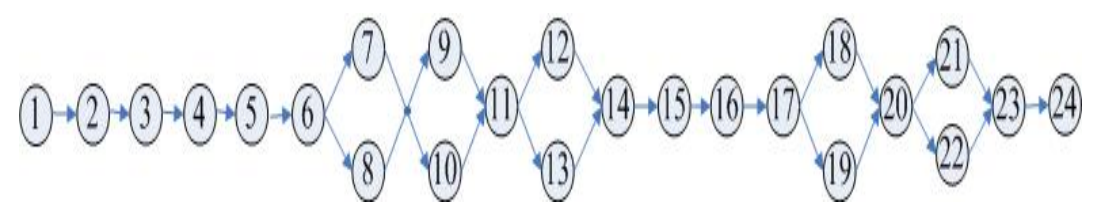

Fig. 4. X4105BC's assembly sequence diagram after optimization

\subsection{Simulation Model After Optimization}

After adjustment and optimization the assembly route includes 24 working procedures, which are divided into four workstations, each workstation need only one operating workers to complete assembly tasks. The optimized simulation model shown in Figure 5, 6,7,8,9.

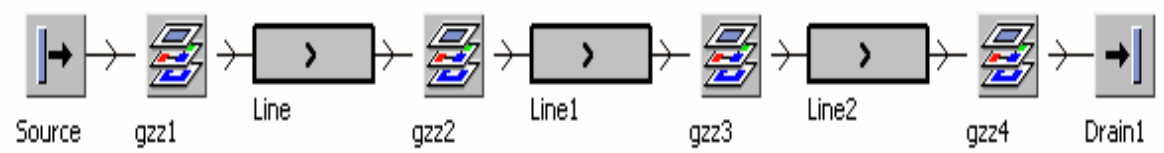

Fig. 5. X4105BC's assembly eM-Plant simulation model after optimization

Here the "Source" means diesel engine supply; "Line" means powered conveyor which transfer diesel engine between workstations, Drain means the completion of the assembly line, gzz1, gzz2, gzz3 and gzz4, means the four workstation after optimization respectively.

Workstation 1 include six working procedures, which are first wash, second wash, camshaft bushes, crank watts, crankshaft, cylinder. The Source1, Source2, Source3 mean the required component supply, the eM-plant simulation model of the Workstation 3 shown in Fig.6.

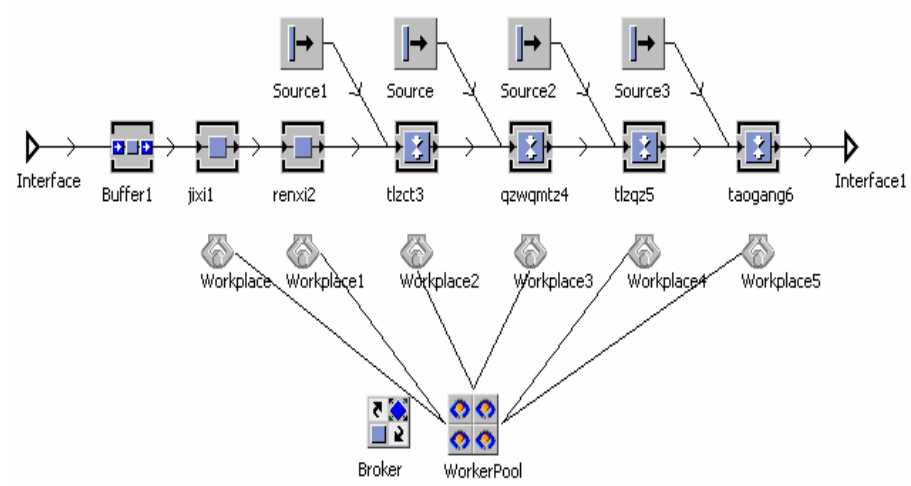

Fig. 6. eM-Plant simulation model of workstation 1 after optimization 
Workstation2 include six working procedures, which are piston, flywheel, oil pipes, cooler, side cover, flywheel and other six processes, the eM-plant simulation model of the Workstation 3 shown in Fig.7.

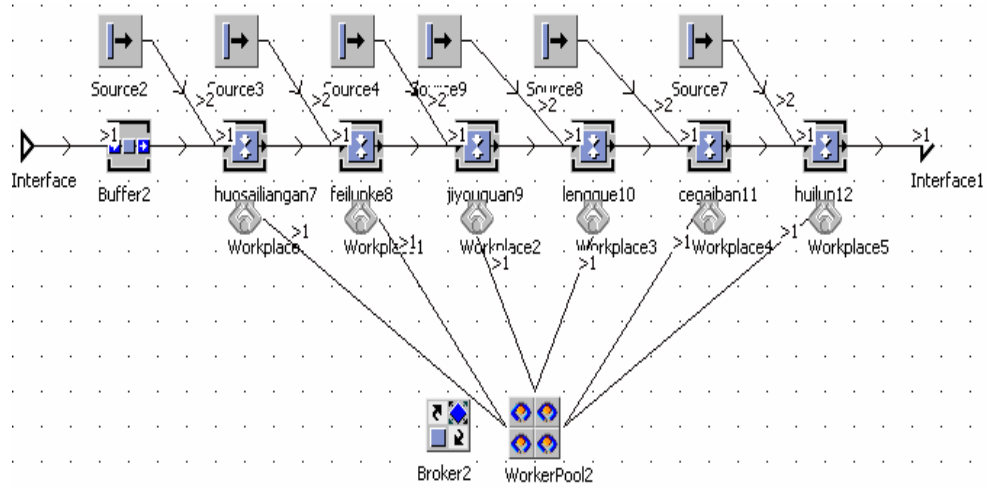

Fig.7. eM-Plant simulation model of workstation 2 after optimization

Workstation3 include six working procedures, which are oil pan, starter motor, cylinder head, water pump, high pressure oil pump diesel filter, how the gear into the trachea, the eM-plant simulation model of the Workstation 3 shown in Fig.8.

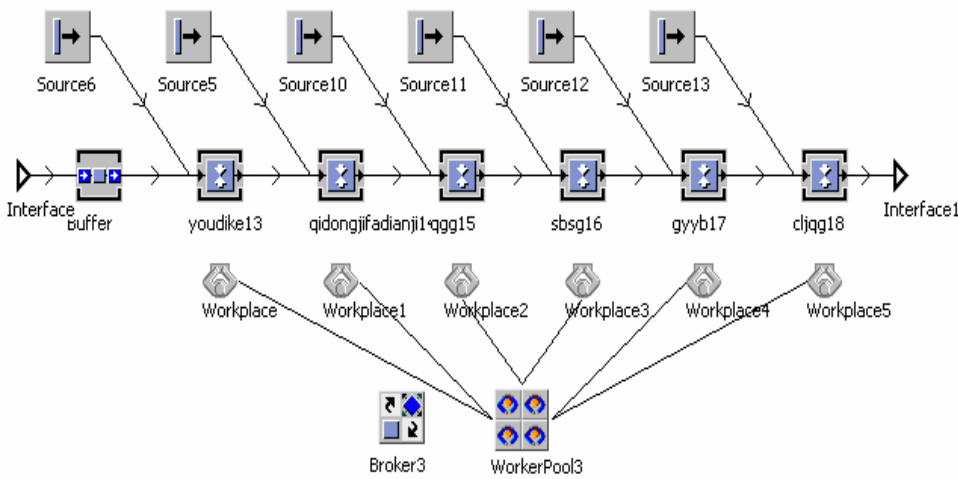

Fig. 8. eM-Plant simulation model of workstation3 after optimization

Workstation4 includes six working procedures, which are the arm rings, gear cover, injector cylinder covers, exhaust pipe, pulleys oil filter, oil pipes, the eM-plant simulation model of the Workstation 4 shown in Fig.9. 


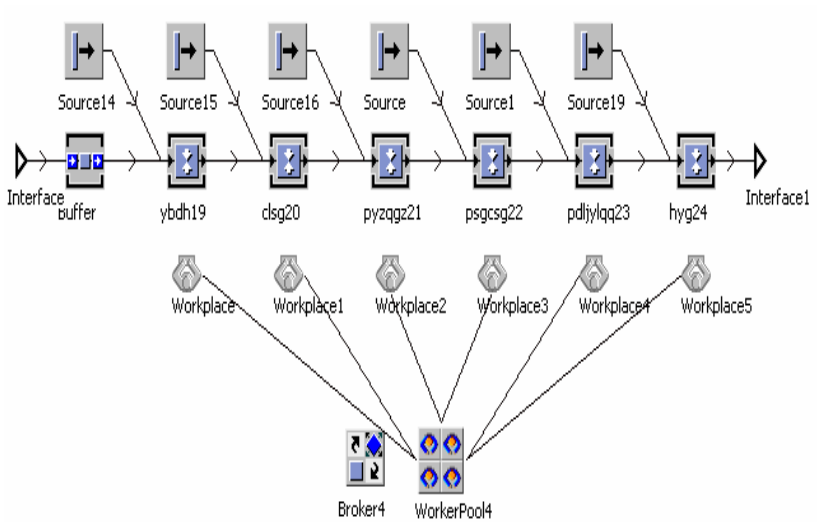

Fig. 9. eM-Plant simulation model of workstation4 after optimization

\subsection{Simulation Results After Optimization}

Once the optimization simulation model is completed, run the simulation model, we can get the interesting statistics after the simulation, hear we take the workstation's working balance as an example. After the optimization, the workstation's working balance histogram is shown in Fig.10. The blue heap in the workstation's working balance histogram means all processing time for each workstations, the red heap means the total balance loss, it is clearly that after optimization,the assembly line's balance lost is improved greatly and the working procedures processing is in a proportional way, which can lead a effective drop-down WIPs.

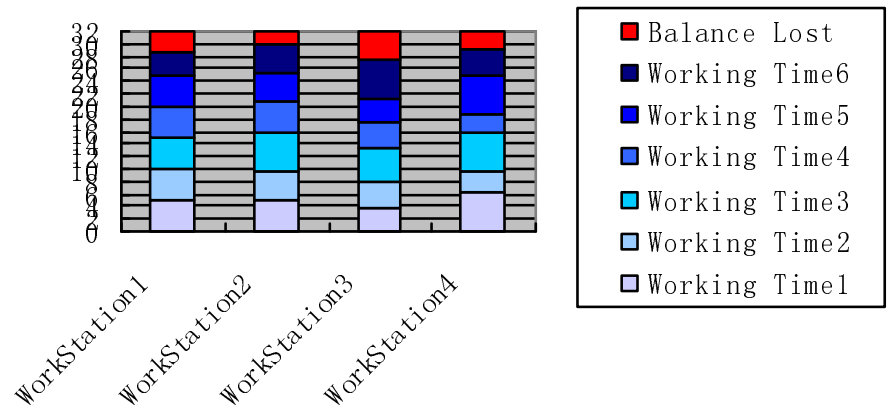

Fig. 10. Assembly line balance histogram after optimization

After optimization, the number of workers in the assembly line can be cut down largely, and the worker's working efficiency has greatly improved from $65.41 \%$ to $96.19 \%$ on the average. And also, the WIP's number and occupation rate in each buffer has greatly reduced from 65.834 to 9.024 on the average, which speeds up the enterprise's logistics working efficiency greatly. 


\section{Conclusions}

Many enterprise are facing production logistics problem such as WIP controlling, long production cycle ,low working efficiency and devilry delay etc, Handling these problem always means production mode adjustment which results in production line shutdown and assembly line re-balance, this may bring enormous loss if not handled carefully and rightly. With professional simulation software such as eM-Plant,we can build production logistics simulation model in a modular, hierarchical way, eM-Plant 's simulation mode and it's statistics, data analysis and optimization capabilities can offer powerful support to for enterprise's decision making.

\section{Acknowledgements}

This study was supported by JiangXi Natural Science Foundation(No.2009GZS0015), JiangXi Educational Committee Foundation(No.GJJ10467), National High-tech Research and Development Program of China(863 program) (No. 2009AA04Z106) and Jiangxi Key Laboratory of Ministry of Education for Conveyance and Equipment.

\section{References}

1. Liu, G.-F., Ma, T.: EM-Plant-Based Washing Machine Assembly Line Balancing Analysis. Industrial Engineering and Management 3(200), 104-108

2. Ma, Y., Zhang, W.: Simulation Based Job Shop Scheduling Optimization. System Simulation 19(200), 4548-4552

3. Zhao, B., Cheng, Y.: Sedan Production Line Assembly Process Planning Simulation System. System Simulation 3, 198-203 (2003)

4. Cao, W., Zhu, Y.: Mixed model general assembly of dynamic programming and simulation. Computer Integrated Manufacturing Systems 4, 123-126 (2006)

5. Zheng, S.: Production Line Simulation Technology. Weapon Industry Automation (4), $22-$ 23 (2004) 